\title{
The Ancient Bristlecone Pines of Methuselah Walk, California, as a Natural Archive of Past Environment.
}

\author{
Malcolm K. Hughes, Gary Funkhouser and Fenbiao Ni
}

Laboratory of Tree-Ring Research, University of Arizona; mhughes@|trr.arizona.edu, gary@|trr.arizona.edu, fenbiao@|trr.arizona.edu

\section{Longest Tree-Ring Chronology}

Almost fifty years ago, Edmund Schulman (1956) recognized the unique longevity of the bristlecone pines (Pinus longaeva) of the White Mountains on the border between California and Nevada. Alerce (Fitzroya cupressoides) in south-central Chile is the only other tree species to even approach the 5,000-year lifespan of the bristlecone pine. Even after death, the pines may remain standing for millennia, and their tight-ringed, resinous wood may survive several thousand years after falling to the ground. The persistence of this wood results from the combination of its properties with the cool, dry conditions that exist for much of the year at elevations of $2,800-3,400$ meters in the severe rain shadow of the Sierra Nevada. In Methuselah Walk (Fig. 1 and cover photograph), many hundreds of

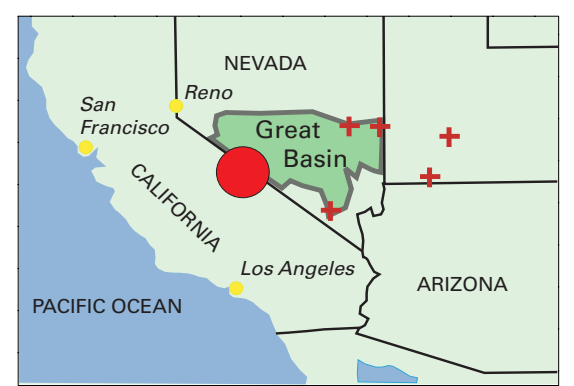

Fig. 1: Location map showing the position of Methuselah Grove (red circle), the other five lower forest border, moisture sensitive long chronologies (red plus signs), and the boundary of Nevada Division 3 (heavyline).

ancient living trees, dead snags and logs have been sampled over the decades. The oldest pieces of wood were alive 11,000 years ago, and Ferguson (1969) used the relict wood to extend Schulman's treering chronology to the beginning of the seventh millennium BC. Dendrochronologically dated material from this site provided the basis of the

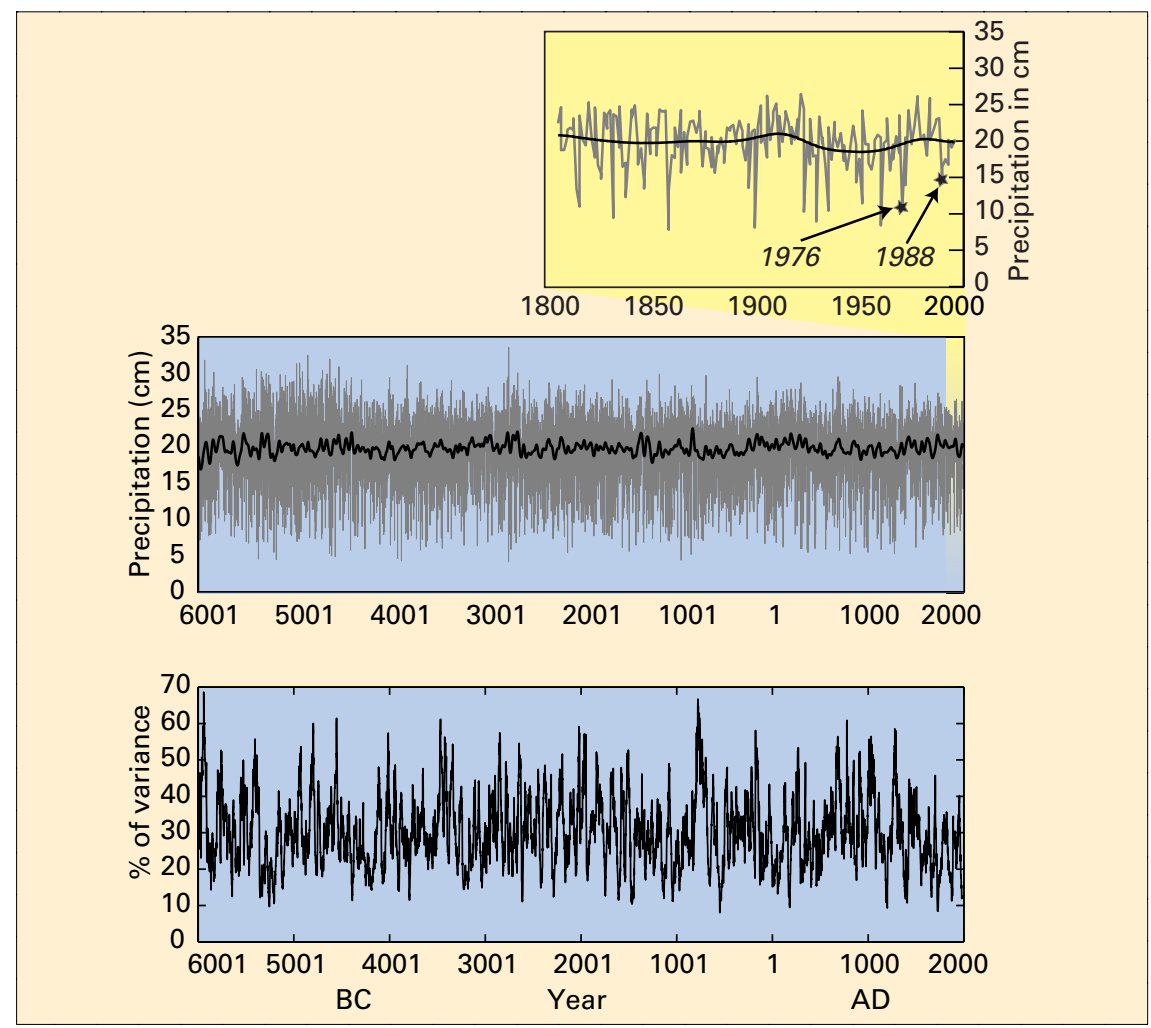

Fig. 2: Upper and middle panel: the reconstruction of Nevada Division 3 July through June precipitation based on the Methuselah Walk bristlecone pine chronology. The year-by-year reconstruction is shown in gray. The thicker, black line shows the reconstruction smoothed by a 50-year low-pass Gaussian filter. Lower panel: the percentage of total chronology variance accounted for by the 3-7 year waveband over a moving 30-year window in the Methuselah Walk chronology.

calibration of the radiocarbon timescale in the 1960s, and so played an important role in the chronological revolution that swept the study of Holocene environments and human prehistory. The Menthuselah Walk provides the longest single-site treering chronology in the world.

\section{Variability in Precipitation}

The new version of the chronology reported by Hughes and Funkhouser (1998) is strongly replicated, with at least 10 or more samples for every year since $6,000 \mathrm{BC}$ up to AD 1995. Due to the strongly moisture-stressed and variable nature of the site, the cross-dating between the trees at Methuselah Walk is extremely clear, and so it can be inferred that there is a climate signal in the variability of the rings. Intensive investigations of the autecology and dendrochronology of bristlecone pine by Fritts, LaMarche and Graybill and others provided the basis for an almost 7,996-year long reconstruction of precipitation in the southern portion of the Great Basin (Fig. 1, Hughes and Graumlich 1996; Hughes and Funkhouser 1998). The tree rings account for $40 \%$ of the interannual variability of precipitation, and clearly capture decadal and multidecadal variability, as exemplified by the regional switch to wetter conditions after 1976 (Fig. 2, upper panel). They also show the multiyear drought of the late 1980s, which caused serious problems in water-hungry California. In fact, the reconstruction shows that this drought was far from exceptional, hundreds more severe droughts were recorded in the last eight thousand years. The reconstruction captures the character of precipitation variation in this very dry region, with striking interannual variability (Figure 2, middle panel), and a small proportion of decadal and longerscale fluctuation.

Hughes and Graumlich (1996) pointed out that the precipitation re- 


\section{Science Highlights}

construction based on the Methuselah Walk chronology contains two multidecadal droughts in the period from the tenth to fourteenth centuries $A D$. These droughts corresponded to low stands of nearby Mono Lake as reported from geomorphological evidence by Scot Stine (1994). These same droughts were seen in independent reconstructions based on tree-ring width chronologies by Graumlich and by Graybill and Funkhouser based on other tree species in the neighboring Sierra Nevada, and in stable isotope ratios in the Methuselah Walk wood reported by Leavitt. The Methuselah Walk ringwidth data, and the isotope data also correspond to Stine's geomorphic data in another, revealing, respect. All three records show the two major, sustained droughts ending in a decade or two of very unusual moisture excess.

Further support is given to the veracity of these century-scale and longer fluctuations in a reconstruction based on the Methuselah Walk chronology by comparison with another, more than 1,700-year long, reconstruction of precipitation in the same portion of the southern Great Basin, for the same July-June period (Hughes and Funkhouser 1998). It is based on six chronologies, including Methuselah Walk, all well replicated for at least 1,700 years. The reconstruction accounts for $48 \%$ of precipitation variance and has century-scale fluctuations very similar to the Methuselah Walk-based reconstruction (Fig. 3). This pattern is almost unchanged even if the MethuselahWalk-based series is excluded from the multi-chronology-based reconstruction. There was clearly a greater incidence of intense, persistent, moisture deficits after AD 400 and before approximately AD 1500 than in the periods immediately before and after. Hughes and Funkhouser (op.cit.) point out that "there is a broad similarity between the multicentury pattern over the last 1600 years reconstructed here for the Great Basin, and the broad patterns of accumulation measured on the high-elevation ice-caps at Quelccaya in Peru, and Dunde in Tibet (Thompson, 1996). This could be

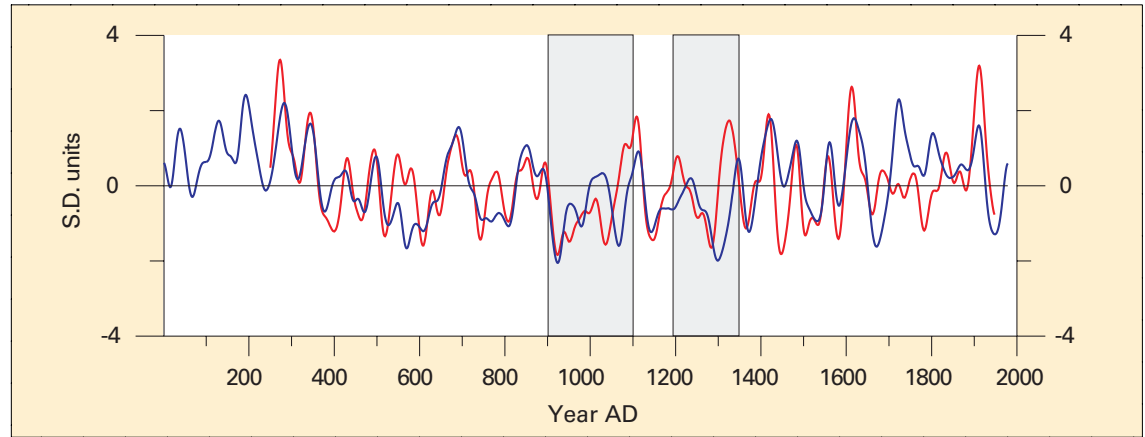

Fig. 3: The 50-year smoothed Nevada Divisions 3 precipitation reconstructions based on only the Methuselah Walk chronology (blue line) and on all six lower forest border chronologies (red line). The reconstructions have been converted to z-scores. The gray areas indicate the times of low stands of Mono Lake identified by Stine (1994).

mere coincidence, or it may represent a feature of variability in the hydrological cycle on a global scale."

\section{ENSO-related Fluctuations}

In recent years, PAGES scientists have reported convincing evidence of regime-like behavior in the last two centuries in the EI Niño-Southern Oscillation phenomenon (ENSO), using coral bands and tree rings. Although the regional expression of ENSO effects in eastern California and the Great Basin are complex, the region is part of a large, southwestern quarter of the United States where winter halfyear precipitation is strongly correlated with the Southern Oscillation Index (SOI) during the instrumental period. In order to identify potentially ENSO-related fluctuations in the Methuselah Walk chronology, we used a band-pass filter designed to conserve variability on 3 to 7 year timescales, which are empirically associated with ENSO. This filtered version of the reconstruction has a correlation pattern with global surface November through April temperatures for the period 1959-1994 that is strongly reminiscent of the pattern associated with ENSO. The proportion of the total variance of the reconstruction that is accounted for by this 3-7 year waveband in a 30-year moving window fluctuates in a distinctly regime-like manner over the past 8,000 years (Fig. 2, lower panel). ENSO-timescale variance has been as much as $60 \%$ and as little as $10 \%$ of total variance on occasion. There is no indication of an absence of ENSO-timescale variability in the early part of the reconstruction. The periods since AD
1500 and before AD 400 are marked by relatively limited ENSO-timescale variability. These periods correspond to times of enhanced occurrence of severe, sustained droughts.

\section{Human Impact}

Understanding the causes and predictability of the variability of precipitation is of great importance to the burgeoning human population of California, and its neighboring states. The questions that arise from the dendroclimatology of the trees of Methuselah Walk are only likely to be resolved by using the characteristic PAGES approach of large geographic scale comparison and integration of multiple proxy records, and exploration of their climatic signals using coupled ocean-atmosphere models.

\section{REFERENCE}

Ferguson, C.W., 1970, Dendrochronology of bristlecone pine,Pinus aristata, establishment of a 7484 year chronology in the White Mountains of eastern-central California. In: I.U.Olsson. Radiocarbon Variations and Absolute Chronology. Nobel Symposium 12, Stockholm: Almqvist and Wiksell. p 237-259.

Hughes, M.K. and Funkhouser, G., 1998, Extremes of moisture availability reconstructed from tree rings for recent millennia in the Great Basin of Western North America. In: Beniston M, Innes JL, editors. The Impacts of Climate Variability on Forests. Berlin: Springer. p 99-107.

Hughes, M.K. and Graumlich, L.J., 1996, Multimillennial dendroclimatic records from western North America. In: Bradley RS, Jones PD, Jouzel J, Editors. Climatic variations and forcing mechanisms of the last 2000 years. Berlin: Springer Verlag. p 109-24.

The 8000-year reconstruction reported here is available at: http://www.ngdc.noaa.gov/paleo/drought/ drght_graumlich.html

Schulman, E., 1954, Longevity under adversity in conifers, Science, 119, 396-399.

For full references please consult:

www.pages-igbp.org/products/newsletters/ref2002_1.htm 